\title{
Optimising Environmental Performance of Symbiotic Networks Using Semantics
}

\author{
Nikolaos Trokanas*, Franjo Cecelja, Mingyen Yu, Tara Raafat \\ PRISE Group, Chemical \& Process Engineering, University of Surrey, Guildford, UK \\ n.trokanas@surrey.ac.uk
}

\begin{abstract}
Industrial Symbiosis (IS) is an ecological approach aiming to promote waste valorization opportunities. To date, efforts related to IS process rely on data generated in the aftermath of IS network formation. We propose the integration of the process of screening of IS network options and optimisation of respective environmental performance with the use of semantics.
\end{abstract}

Keywords: Industrial Symbiosis, Optimisation, Environmental, Metrics.

\section{Introduction}

Industrial Symbiosis (IS) is an innovative approach that brings together companies from different sectors in an effort to promote the valorisation of waste, improvement of resource efficiency and reduction of environmental impact. IS also aims in delivering benefits to all participating parties. Several efforts (Martin et al., 2012; Mattila et al., 2010) have been made to identify and quantify these benefits but mostly based on data generated in the aftermath of the formation of symbiotic networks. Since, the process of identifying of symbiotic networks has been automated and enhanced with the use of semantics (Raafat et al., 2013). Hence in this paper we propose the integration of IS network identification and optimisation of its environmental performance which will allow not only for the pre-assessment of the impact of the symbiotic network but also for providing optimised solutions given the custom user requirements.

\section{Industrial Symbiosis}

Industrial Symbiosis (IS) was developed from the concept of Industrial Ecology. It aims in creating symbiotic networks to process waste by sharing of facilities, water and energy. Ultimately, the establishment of symbiotic synergies produces environmental, social and economic benefits for all parties involved as well as local communities. Current practice of identifying synergies takes place in the form of manual workshops that require mediation by trained practitioners, hence making the process time consuming and expensive. Also, the benefits of symbiotic synergies are assessed from user feedback and after synergies have been established. Predicting benefits beforehand is still a challenge.

\section{IS Metrics}

The metrics currently in use for the evaluation of the performance of IS synergies fall into three categories (Trokanas et al., 2013a): i) environmental, ii) economic and iii) social. Focus of this work is on environmental benefits of IS.More specifically they include: i) Landfill Diversion Savings, ii) Embodied Carbon Impact, iii) Transportation Impact and iv) Virgin Materials Saved. 
Numerous research efforts have been made to quantify environmental impact and benefits, which include techniques such as life cycle analysis (LCA) (Mattila et al., 2010) and flow analysis (Martin et al., 2013).Still, a gap in proposed frameworks and methods has been identified (van Berkel, 2010). More precisely, the proposed techniques focus on the comparison of benefits before and after a symbiotic synergy has been established which inevitably requires intensive monitoring by practitioners and reporting from participants. In this paper, we propose a method that employs semantic technologies and enables the pre-assessment and optimisation of the environmental output of screened symbiotic synergies. To achieve that, five different environmental indicators are calculated and hence converted into monetary metrics for comparison and aggregation.

\subsection{Landfill Diversion Savings}

This metric quantifies re-use of waste instead of landfilling it. It uses the quantity of resource exchanged between participants $i$ and $j, Q_{i, j}$, the disposal cost for the resource $D C_{i, j}$ and the landfill tax $L T$.

$L D S=\sum_{i, j}^{\text {Resource }} Q_{i, j} *\left(D C_{i, j}+L T\right)$

\subsection{Embodied Carbon Impact}

This metric accounts for the embodied carbon of the resource exchanged between participants $i$ and $j$. Re-used and recycled materials have lower embodied carbon, hence lower impact. It uses quantities $Q_{i, j}$ of exchanged resources, embodied carbon value of the resources $E C_{i, j}$ and the credit price of carbon dioxide $C O_{2}^{P}$ as formed by the carbon trading scheme:

$E C I=\sum_{i, j}^{\text {Resource }}\left(Q_{i, j} * E C_{i, j} * C O_{2}^{P}\right)$

\subsection{Transportation Impact}

Transportation of resources between participants also affects the environmental performance of a synergy. This metric is calculated from the quantities $Q_{i, j}$ of the exchanged resources, the factor $T F_{i, j}$ characterizing the emission of particular mode of transportation, the distance between IS participants $i$ and $j$ and the credit price of carbon dioxide $\mathrm{CO}_{2}^{P}$.

$T I=\sum_{i, j}^{\text {synergy }}\left(Q_{i, j} * T F_{i, j} *\right.$ distance $\left._{i, j} * C O_{2}^{P}\right)$

\subsection{Virgin Materials Savings}

This metric quantifies replacement of virgin materials by waste. For that, it uses capacities $C_{i, j}$ between participants $i$ and $j$, price of the resource as a raw material $F P_{i, j}$ and price as a recyclate $R P_{i, j}$.

$V M S=\sum_{i, j}^{\text {Synergy }} C_{i, j} *\left(F P_{i, j}-R P_{i, j}\right)$ 


\section{Identifying and Optimising Synergies}

\subsection{Identifying Synergies}

Synergies are identified by semantic matching of user profiles, the process supported by the domain ontology and otherwise performed by practitioners (Raafat et al., 2012a). The domain ontology (Figure 1) represents the domain of IS (Trokanas et al., 2012), which includes the resources (waste, material, and energy), processing technologies, participants and other necessary peripheral information, such as geographic location, physical form and unit of measurement. The domain ontology is used for acquisition of user profile data, i.e. type of resource/solution available, location, availability period, pattern of supply, quantity, for calculation of similarity between user profiles and also for modelling of information used for performance evaluation and optimisation.

More precisely, each participant is represented as the instance of the domain ontology and then described by a separate ontology, the Semantic Web Service Ontology modelled in OWL-S (Martin et al., 2004) for more elaborated matching, as demonstrated in Figure 2 (Raafat et al., 2012b).

As such, the process of semantic matching benefits from currently available tacit knowledge embedded in the domain ontology and captured explicit knowledge on participants and enables evaluation of semantic relevance scores (Similarity ${ }_{i, j}$ ) between participantsi and $j$ (Trokanas et al., 2013b). For this, the matching process uses

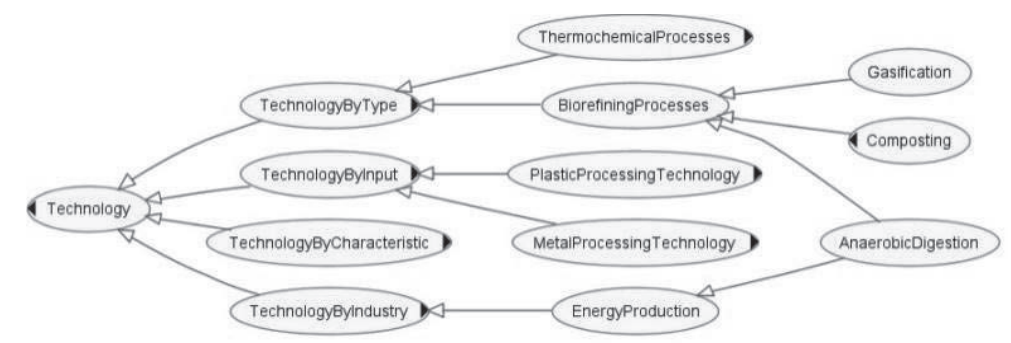

Figure 1. Excerpt of the domain ontology

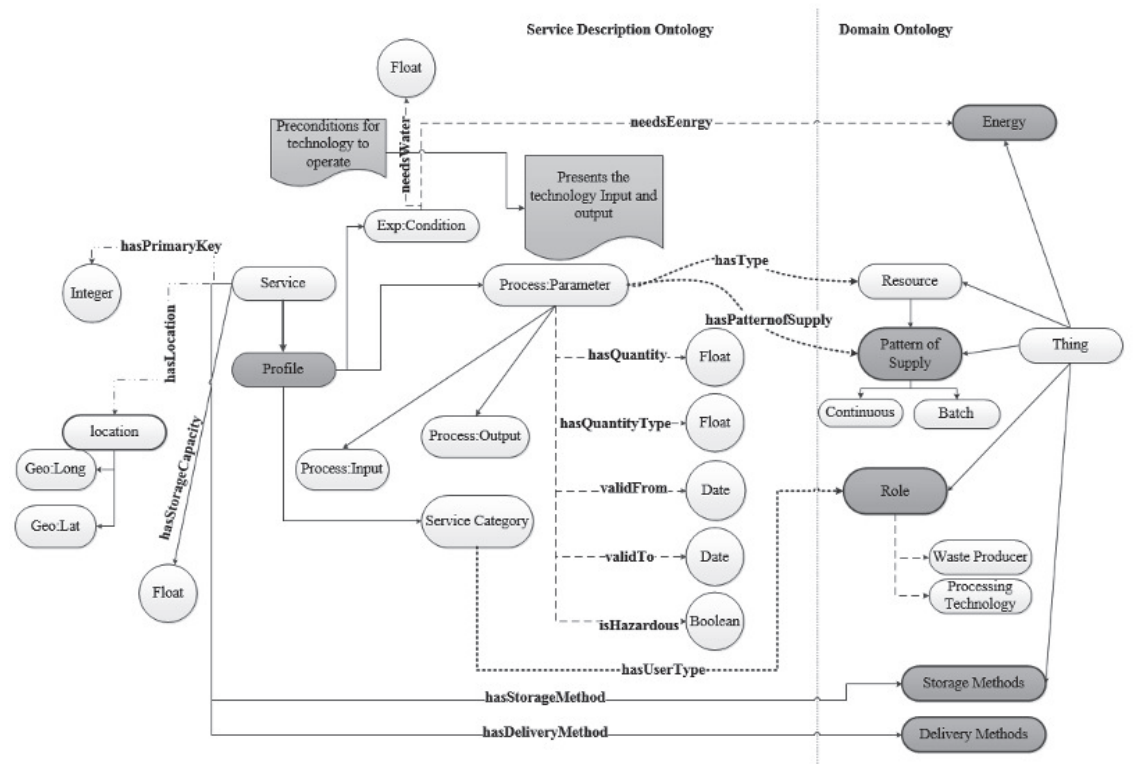

Figure 2. Semantic Web Service Ontology 


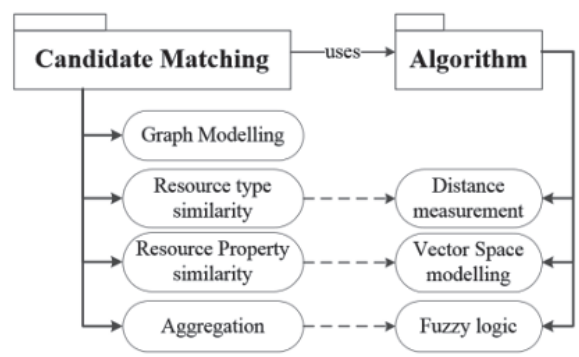

Figure 3. Structure of the Semantic Matching Algorithm

a combination of vector similarity and distance measurement techniques, the scores of which are normalised for informed comparison (Figure 3). After semantic relevance scores have been calculated the network is being optimised in terms of its environmental performance.

\subsection{Optimising Synergies}

The objective function, representing the environmental benefits of the symbiotic networks, of the optimisation model is derived from the aggregation of the metrics given by Eqs. (1) - (4) as:

$E N V I=L D S-E C I-T I+V M S$

Linear programming is employed to maximise the environmental benefits of the synergy. The constraints of the optimisation problem stem in availability and demand of resources. It is worth noting that the demand or availability of the participant that initiates a request must be satisfied. Other participants of the network act as facilitators.

\subsection{Final Aggregation}

After the optimisation of the environmental performance, ENVI is normalised by observing Eq. (6) and the optimised results are aggregated with the semantic results and presented to the user as a single score.

$E N V I_{i, j}^{\text {normalised }}=\frac{E N V I_{i, j}-E N V I_{\min }}{E N V I_{\max }-E N V I_{\min }}$

The normalised ENVI score is aggregated with similarity scores between participants, using weighting factors that have been established through practice:

Final Aggregated Score $_{i, j}=\left(70 \% *\right.$ Similarity $_{i, j}+30 \% *$ ENVI $\left._{i, j}^{\text {normalised }}\right)$

The similarity score required for this calculation is calculated as a percentage of the available quantities:

Similarity $_{\text {optimised network }}=\sum_{i, j}^{\text {synergy }}$ Similarity $_{i, j} * \frac{Q_{i, j}^{\text {optimised }}}{Q_{i, j}} * 100 \%$

\section{Case Study}

A number of users registered with the system have provided information as in Table 1. The request to form symbiotic network is initiated by User 9 who needs $810 \mathrm{~kg}$ of Polypropylene. There are two other sources of Polypropylene, User 2 and User 5. Following the backward chaining method (Raafat et al, 2013) User 2, a solution provider, matches against User 6 and User 1 who have available Propylene. Based on this information, the semantic relevance scores are shown in Table 2. After all the 
Table 1. Registration Details

\begin{tabular}{cccccccccc}
\hline ID & $\begin{array}{c}\text { User } \\
\text { Type }\end{array}$ & $\begin{array}{c}\text { Resource } \\
\text { Output }\end{array}$ & $\begin{array}{c}\text { Resource } \\
\text { Input }\end{array}$ & $\begin{array}{c}\text { Output } \\
\text { Quantity }\end{array}$ & Lat & Lon & Valid from & Valid to & $\begin{array}{c}\text { Pattern } \\
\text { of } \\
\text { Supply }\end{array}$ \\
\hline $\mathbf{6}$ & RP & Propylene & - & 550 & 22.8286 & 38.5188 & $01 / 01 / 2013$ & $01 / 01 / 2015$ & b \\
$\mathbf{1}$ & RP & Propylene & - & 850 & 22.8923 & 38.4459 & $01 / 03 / 2013$ & $01 / 03 / 2014$ & b \\
$\mathbf{9}$ & RC & - & $\begin{array}{c}\text { Poly- } \\
\text { propylene }\end{array}$ & 810 & 22.9165 & 38.6466 & $01 / 06 / 2013$ & $01 / 06 / 2015$ & c \\
$\mathbf{2}$ & SP & $\begin{array}{c}\text { Polypropy- } \\
\text { lene }\end{array}$ & Propylene & 830 & 22.8563 & 38.5251 & $01 / 06 / 2013$ & $01 / 01 / 2015$ & b \\
$\mathbf{5}$ & RP & $\begin{array}{c}\text { PP Scrap } \\
\text { Bags }\end{array}$ & - & 600 & 22.9380 & 38.4323 & $10 / 09 / 2013$ & $01 / 07 / 2014$ & c \\
\hline
\end{tabular}

potential synergies have been identified the respective environmental performances are calculated (Table 2) and used as a benchmark.

In the following step the optimisation process is employed to maximise the environmental performance of the symbiotic network. One more advantage of the employment of optimisation is that it enables decomposition of the quantities. The objective function (Eq. 5), representing environmental benefits, is maximised, given Eqs. (1-4).The optimised results are presented in the map presented in Figure 4. The optimised quantities are given in Table 3, these quantities result in optimised ENVI = 873,662 .

Observing Eq.(6), the optimised ENVI and the results in Table 3, all results are normalised as shown in Table 4. After normalisation, the similarity and normalised ENVI scores are aggregated into a single metric observing Eq.(7). Finally, the similarity score for the optimised network is calculated from Eq.(8).

The optimised network which has the best environmental performance is the most relevant. Other potential synergies follow with lower aggregated scores.

Table 2. Semantic Matching Results

\begin{tabular}{ccc}
\hline Synergy & Score & ENVI \\
\hline $5-9$ & 0.9017 & 782,172 \\
$1-2-9$ & 0.8351 & 294,393 \\
$6-2-9$ & 0.8297 & 129,908 \\
\hline
\end{tabular}

Table 3. Optimised Quantities

\begin{tabular}{cc}
\hline Synergy & Quantity \\
\hline $5-9$ & 600 \\
$1-2$ & 0 \\
$6-2$ & 280 \\
$2-9$ & 210 \\
\hline
\end{tabular}

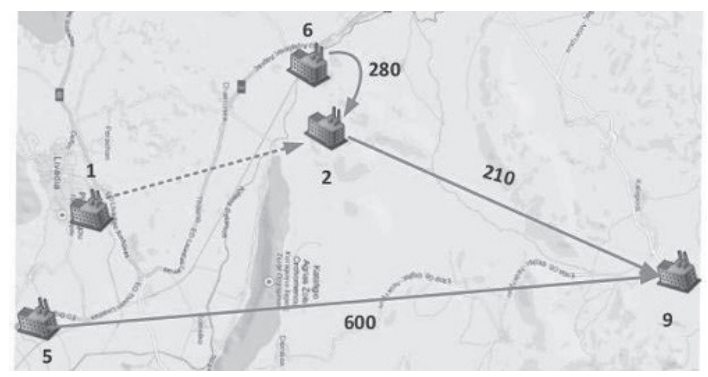

Figure 4. Optimised network results 
Table 4. Normalised Results and Aggregated Results

\begin{tabular}{ccccc}
\hline Synergy & ENVI & Similarity & $\begin{array}{c}\text { Norm } \\
\text { ENVI }\end{array}$ & $\begin{array}{c}\text { Aggregated } \\
\text { Scores }\end{array}$ \\
\hline $5-9$ & 782,172 & 0.9017 & 0.8770 & 0.8844 \\
$1-2-9$ & 294,393 & 0.8351 & 0.2212 & 0.4053 \\
$6-2-9$ & 129,908 & 0.8297 & 0.0000 & 0.2489 \\
Optimised Network & 873,662 & 0.88298 & 1.0000 & 0.9648 \\
\hline
\end{tabular}

\section{Conclusions}

The presented approach enables the pre-assessment of IS network. It also allows the optimisation of environmental output of IS networks. For that, it employs semantic technologies that also automate IS practice. Currently, the presented method takes into account only environmental benefits. This work can serve as a framework for further development that will include other aspects of industrial symbiosis such as economic and social benefits.

\section{References}

D. Martin, 2004, OWL-S: Semantic Markup for Web Services. <www.w3.org/Submission/OWL$\mathrm{S}>$, accessed on $12 / 11 / 2013$.

M. Martin, N. Svensson, M. Eklund,2012, Who gets the benefits? An approach for assessing the environmental performance of industrial symbiosis. In Greening of Industry Network: Support your future today! Turning environmental challenges into business opportunities.

T.J. Mattila, S. Pakarinen, L. Sokka, 2010, Quantifying the Total Environmental Impacts of an Industrial Symbiosis-a Comparison of Process-, Hybrid and Input- Output Life Cycle Assessment, Environmental Science and Technology, 44, 11, 4309-4314.

T. Raafat, N. Trokanas, F. Cecelja, X. Bimi, 2013, An ontological approach towards enabling processing technologies participation in industrial symbiosis, Computers \& Chemical Engineering, 59, 33-46

T. Raafat, F. Cecelja, A. Yang, N.Trokanas, 2012a, Semantic Support for Industrial Symbiosis Process, Computer Aided Chemical Engineering, 30, 452-456

T. Raafat, N. Trokanas, F. Cecelja, A. Kokossis, A. Yang, 2012b, Semantically-enabled Formalisation to Support and Automate the Application of Industrial Symbiosis, Computer Aided Chemical Engineering, 31, 1055-1059

N. Trokanas, T. Raafat, F. Cecelja, A. Kokossis, A. Yang,2012, Semantic Formalism for Waste and Processing Technology Classifications Using Ontology Models, Computer Aided Chemical Engineering, 30, 167-171

N. Trokanas, F. Cecelja, T. Raafat, 2013a, Semantic Approach for Pre-assessment of environmental indicators in Industrial Symbiosis, Journal of Cleaner Production, DOI: 10.1016/j.jclepro.2013.12.046.

N. Trokanas, T. Raafat, F. Cecelja, A. Kokossis, 2013b, OFIS - Ontological Framework for Industrial Symbiosis, Computer Aided Chemical Engineering, 32, 523-528

R.Van Berkel, 2010, Quantifying sustainability benefits of industrial symbioses, Journal of Industrial Ecology, 14, 3, 371-373. 